\title{
"The influence of financial technologies on the global financial system stability"
}

$\begin{array}{ll} & \text { Galyna Azarenkova iD https://orcid.org/0000-0003-0101-2989 } \\ \text { R http://www.researcherid.com/rid/M-5272-2015 } & \text { Iryna Shkodina iD https://orcid.org/0000-0003-4035-3188 } \\ \text { AUTHORS } & \text { Borys Samorodov iD https://orcid.org/0000-0002-5267-1178 } \\ & \text { Maksym Babenko id https://orcid.org/0000-0001-6792-3465 } \\ & \text { Iryna Onishchenko iD https://orcid.org/0000-0001-8186-6225 }\end{array}$

Galyna Azarenkova, Iryna Shkodina, Borys Samorodov, Maksym Babenko and ARTICLE INFO Iryna Onishchenko (2018). The influence of financial technologies on the global 15(4), 229-238. doi:10.21511/imfi.15(4).2018.19

\begin{tabular}{ll} 
DOI & http://dx.doi.org/10.21511/imfi.15(4).2018.19 \\
\hline RELEASED ON & Wednesday, 28 November 2018 \\
\hline RECEIVED ON & Tuesday, 04 September 2018 \\
\hline ACCEPTED ON & Friday, 12 October 2018 \\
\hline LICENSE & (cc) EY \\
\hline JOURNAL & This work is licensed under a Creative Commons Attribution 4.0 International \\
\hline ISSN PRINT & License \\
\hline ISSN ONLINE & "Investment Management and Financial Innovations" \\
\hline PUBLISHER & $1810-4967$ \\
\hline FOUNDER & $1812-9358$ \\
\hline
\end{tabular}

NUMBER OF REFERENCES

20

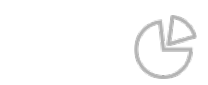

NUMBER OF FIGURES

3

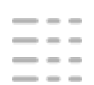

NUMBER OF TABLES

0

(C) The author(s) 2022. This publication is an open access article. 


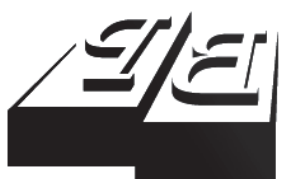

BUSINESS PERSPECTIVES

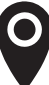

LLC "CPC "Business Perspectives" Hryhorii Skovoroda lane, 10, Sumy, 40022, Ukraine

www.businessperspectives.org

Received on: $4^{\text {th }}$ of September, 2018 Accepted on: 12 $2^{\text {th }}$ of October, 2018

(c) Galyna Azarenkova, Iryna Shkodina, Borys Samorodov, Maksym Babenko, Iryna Onishchenko, 2018

Galyna Azarenkova, Doctor of Economics, Professor, Head of the Department of Finance, Banking and Insurance, Kharkiv Educational and Scientific Institute of SHEI "Banking University", Ukraine.

Iryna Shkodina, Doctor of Economics, Assistant Professor Professor of the Department of International Business and Economics, V. N. Karazin Kharkiv National University, Ukraine.

Borys Samorodov, Doctor of Economics, Professor, Director of Kharkiv Educational and Scientific Institute of SHEI "Banking University”, Ukraine.

Maksym Babenko, Ph.D. Student, SHEI "Banking University", Ukraine.

Iryna Onishchenko, Ph.D. Student, SHEI “Banking University”, Ukraine.

\section{(ㄷ) (i)}

This is an Open Access article, distributed under the terms of the Creative Commons Attribution 4.0 International license, which permits unrestricted re-use, distribution, and reproduction in any medium, provided the original work is properly cited.
Galyna Azarenkova (Ukraine), Iryna Shkodina (Ukraine), Borys Samorodov

(Ukraine), Maksym Babenko (Ukraine), Iryna Onishchenko (Ukraine)

\section{THE INFLUENCE OF FINANCIAL TECHNOLOGIES ON THE GLOBAL FINANCIAL SYSTEM STABILITY}

\begin{abstract}
The analysis of the financial technologies introduction has proved that their application over-complicates the institutional structure of the global financial system. As a result, usual functional relationships cease to operate, new institutes and interdependencies appear, and systemic risks increase. In this context, the system instability increases, resulting in a transition to a new institutional status. The analysis of the financial technologies impact on the stability of financial system shows that the lack of institutional support for new financial technologies is the most important catalyst for the financial industry destabilization and the formation of financial bubbles in various market segments.
\end{abstract}

The ways to reduce the negative impact of financial technologies on the financial system stability (such as development of international prudential standards; revision of the licensing regime for financial companies; "regulatory sandboxes", which test new technologies, business models and algorithms underlying the Fintech innovations; legal regulation of ownership of digital tokens; and clear definition of the blockchain technology in various areas of life, etc.) have been proposed.

\section{Keywords}

JEL Classification

digital economy, FinTech, cryptocurrencies, economic bubbles

E44, G10, G15

\section{INTRODUCTION}

The financial globalization of economic systems, the increased number of the global financial market participants and their rapid interaction influenced by modern technologies development lead to the growing institutional complexity of the global financial system. As a result, more opportunities are created for the financial system development. However, the increased complexity of the system results in higher synchronization between its various parts, strengthening the nonlinear correlations, unpredictable consequences and the accumulation of economic imbalances, both at the national and international levels.

After the 2008 financial crisis, the financial industry has actively begun implementing various digital innovative approaches. They have made the basis for financial technologies (FinTech or fintech), i.e. technological innovations in the field of financial services.

Initially, financial technologies (alternative payment systems and lending systems, application program interfaces, robo-advisors and chatbots, big data, blockchain, cryptography and artificial intelligence, etc.) were developed at the level of startups and non-financial compa- 
nies, which used the recent developments to provide better financial services. However, their effectiveness, the speed of processing information (updating information in real time), the relevance and personalization of information forced the traditional participants of the world financial system (primarily banks, investment companies, exchanges, insurance companies, etc.) to actively modernize their activities in order to remain competitive.

Financial technologies increase the financial industry profitability, but, at the same time, they change the architecture of the financial system, which results in a potentially unstable and highly uncertain environment. FinTech threatens the entire global system sustainability, because its implementation makes the established functional links passive, new institutes and interdependencies are distorted and the new ones are created, which leads to unpredictable destabilizing consequences. Domestic and international regulators are not able to withstand new challenges, which is an additional factor in increasing the uncertainty and turbulence of the financial system.

\section{THEORETICAL BASIS}

Recently, more and more work has been done by economists, market analysts and regulatory institutions on exploring financial technologies and their impact on various sectors of the economy. The IMF representatives constantly monitor financial technologies and the dangers related to their introduction (Dong He, 2017). Neng Lai and Van Order (2017) reviewed both positive and negative effects of financial technology on the banking system in China and proposed a ring-fencing method to mitigate risks. Abadi and Brunnermeier (2018) emphasize the competitive preference of the blockchain, but they believe that it can cause instability and incorrect coordination between the participants.

The economists from Sydney and Stockholm (Foley, Karlsen, \& Putninšs, 2018) came to the conclusion that the cryptocurrency market is one of the most unregulated markets in the world. As a result, the black e-commerce market is set close to USD 72 billion, which is comparable to the American and European drug markets. The Deputy Director of the IMF's Department of Currency and Stock Markets believes that the introduction of cryptocurrency in the future may result in a reduction in the demand for central bank money, which will change the paradigm of government currencies and the dominant role of central banks in the financial system (Dong He, 2018). Barrdear and Kumhof (2016) study the role of government institutions in regulating new financial technologies.

Also, the introduction of new financial technologies increases cyber-risks, which are becoming a major threat to financial stability. Approximately USD 731 million in crypto-currency was stolen in the first half of 2018. Bouveret (2018), based on the analysis of various cybercrimes, developed a model to assess cyber-risk for the financial sector. His research suggests that aggregate losses from cybercrime for the financial sector make up $10 \%$ to $30 \%$ of net income.

Given that financial technologies stimulate the creation of financial bubbles in various segments of the financial market, the study of the essence of financial bubbles is quite relevant. John Kenneth Galbraith, in his work "A Short History of Financial Euphoria" (Galbraith, 1994), analyzes financial bubbles and determines their main properties (emergence of a "new financial instrument", short financial memory, mass psychology, speculative euphoria, etc.). The conclusions of this work are confirmed by the 2008 financial crisis and they also describe the current state of the cryptomarket.

At the same time, taking into account the exponential increase of new financial technologies, the effect of their introduction on the financial system transformation is poorly researched, as well as the increase in development uncertainty and the role and functions of regulatory institutions during rapid institutional changes in the financial system. The purpose of the study is to consider the influence of financial technologies on the global financial system stability.

To achieve the purpose of the study, a set of general scientific and special research methods was used: a systematic approach - to substantiate the 
main tendencies of the development of the global financial system influenced by transformation and financial technologies introduction; analysis and synthesis - to reveal the influence of financial technologies on the financial institutions in implementing their functions; expert evaluation to develop approaches to improving the financial technologies institutionalization.

\section{RESULTS}

The increase in the uncertainty and turbulence of the global financial system development (as well as the entire economic system) is due to a new transformational stage. Understanding the features of current state of the global financial system is possible only based on the genesis of socio-economic systems, namely their emergence, formation, development and destruction. At the moment, a new institutional digital system is coming into being. In a crisis state (bifurcation), the economic system suffers from the complication of the institutional structure, it changes its own functions, properties, the number of elements and behavior. It is precisely at the point of bifurcation that qualitative system changes occur and the transition of the old system into a new one begins. This leads to an increase in uncertainty both at the domestic and global levels, as the established functional links cease to operate and new institutions emerge that operate in unpredictable, chaotic and changing conditions.

Financial technologies play a special role in the modern transformation of the financial system, they also help improve financial activity and increase its profitability. The main characteristic of financial technologies is their ability to create innovations in the financial system. It is financial innovations - development of the accounting background, creation of a banking system and modern payment systems, introduction of complex derivatives of financial and credit instruments, modern financial technologies (blockchain, cryptography, quantum computing, Internet of Things, cloud technologies, artificial intelligence, etc.) - that are not only designed to increase profitability, but also to change the financial system fundamentally. According to Will Martin (2018), technological development has led to an increase in labor pro- ductivity almost 30 times from 1760 to now (productivity increased from 100 in 1760 to 3,000 in 2018). The most rapid technological development has been observed in the last 150 years - electricity, automobiles, telephones, television, and Internet increase productivity and output, promote economic growth and increase welfare.

The new digital economy is shaped influenced by new values and people's behavior patterns, which result from the introduction of modern information technology. Thanks to the Internet, a networked economy is formed, in which all subsystems do not have clear boundaries (the same economic entity can operate simultaneously in many subsystems), large data arrays are collected and processed automatically. Given that information is accumulated exponentially and its transmission speed becomes instantaneous, modern information technologies contribute to the rapid spread and replication of imbalances in all spheres.

In this context, financial institutions adapt to technical innovations and are among the first to apply the latest technology, since the speed of obtaining information by market participants affects the operation profitability. In the world, investment in projects related to new financial technologies is increasing (Figure 1).

Banking institutions experience the greatest threat of the financial technologies introduction. According to PricewaterhouseCoopers, 24\% to $28 \%$ of banking business can go to non-financial companies. First of all, it concerns money transfers and payments. One of the directions of financial technologies development is the new payment systems (P2P, P2B), in which the income from payments amounted to USD 2.3 trillion in 2017. As an alternative to bank lending, mobile applications are used to borrow from other people and provide loans themselves. Mobile phone manufacturers (Samsung, Apple), technological giants (Facebook, Alibaba, Google), and telecommunication companies (Airtel, Vodafone) develop their own payment systems. Crowdfunding platforms are used to raise funds (Kickstarter, LendingClub, and Biggggidea (a Ukrainian platform)). To enhance competitiveness, commercial banks actively implement digital banking and provide financial services through mobile and online platforms. 
Source: Based on the Business Insider Intelligence data.

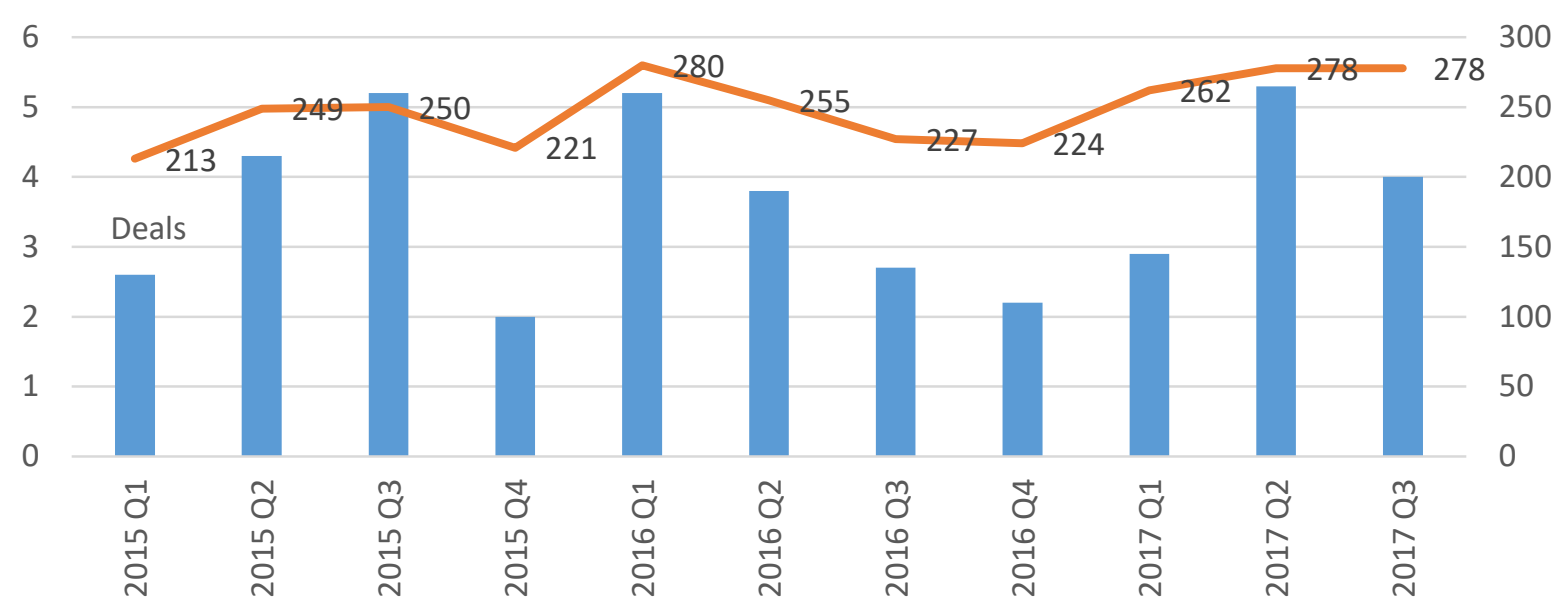

Figure 1. Global investment in new financial technology, in USD billion

Financial assets trading, primarily securities trading, is strongly influenced by financial technology. The emergence of Internet technology has caused virtualization of exchange trading. Since the late 1990s, alternative trading systems (ATSs) have been established on the stock exchanges, which provided market participants with a stock e-commerce. They are called "dark pools", because, from a legal point of view, they are not exchanges and operate in the absence of information transparency (do not provide traders with information on better prices, do not set common rules governing the behavior of traders, do not implement self-regulation). Today's information technology allows financial market participants to make more deals in "dark pools", as a result of which financial markets no longer bring suppliers and consumers of capital in contact, they do not convert savings into investment, distort the pricing mechanism, increase the speculative and risk-taking of the entire financial system. Financial markets change, they lose the traits of traditional markets.

Based on big data analytics technology, which processes huge volumes of both unstructured and structured data, passive and quantum strategies for the purchase/sale of financial assets are developed. With the help of passive strategies, more than 1,700 exchange traded funds (ETFs) with assets of over USD 3.5 trillion are managed globally. According to Bloomberg News, over the next 10 years, the passive giants Vanguard and Blackrock will manage more than USD 20 trillion. Passive investment increases systemic risk, since it is based on two basic algorithms: marginalization of price discovery and herd effect. This can lead to the markets dysfunction and unforeseen deformation of generated schemes of financial flows. Risk is complicated by the problem of ETFs transparency, because, given the complexity of modern financial assets, it is impossible to determine its real value. Consequently, the concentration of capital in volatile and quantum strategies increases investment in ETFs, which causes the formation of financial bubbles and increases the financial system instability.

The development of artificial intelligence and its active usage on the financial market threaten the financial market stability. To increase the financial transactions profitability, the financial business actively invests in the artificial intelligence developments. In 2017, only in North America, artificial intelligence investments ranged from USD 15 to 23 billion, in Asia (mainly China) - from USD 8 to 12 billion, in Europe - from USD 3 to 4 billion. Artificial intelligence analyzes enormous data arrays containing characteristics of operations of billions of economic agents from around the world and predicts the behavior of prices and people. Artificial intelligence is used by various hedge funds and investment companies, it is used for automatic credit approval, automation of trade in various financial assets, as well as for financial fraud detection. According to market analysts, in 25 years, artificial intelligence will manage up to $99 \%$ of investments. At the same time, artificial intelligence becomes a cause of ultra-low volatility, since 
in analyzing an ever increasing amount of data, it is not capable of generating significantly different results and creating similar strategies for different investors. In 2017, the VIX index (Volatility Index or Fear Index) was only 11, while the average number accounted for more than 20. In this context, investors do not pay attention to the fundamental indicators. Consequently, the stock market becomes "trade for the sake of trade", creating a quantity of systemic risks for the global financial system.

Considering that the opportunities for investing in new financial technologies are limited to large firms, concentration of capital, consolidation of firms and market monopolization take place. The largest concentration of capital is in the technological sector. While S\&P500 increased by 331\% in 10 years after the 2008 crisis, Facebook's shares rose by $413 \%$, Amazon's by $2.102 \%$, Apple's by $1.123 \%$, Netflix by $5.349 \%$, and Google's by $586 \%$. All financial sector companies have grown by $617 \%$ since 2008. Thus, another e-commerce bubble is being formed. Considering that 8 technology companies account for more than $15 \%$ of the S\&P500 index and $48 \%$ of NASDAQ 100 , any minor unpredictn able event could lead to a cascading fall of the entire market.

Concentration on the financial market has repeatedly led to crisis phenomena. For example, the cause of the 2007-2008 crisis was the activity of "too big to fail" companies. As the investment discipline became weak, they began to take excessive risk, which increased the systemic risk of the entire financial system. As a result of capital concentration, economic growth is suppressed and inequality intensifies. Over the past 30 years, corporate profits have grown, while corporate investment and labor force participation in GDP decrease, namely the share of wages in gross value added has shrunk by $10 \%$, corporate investment has decreased by $30 \%$, and the share of profit has increased from $2 \%$ of gross value added in 1984 to $15.7 \%$ in 2014 . Consequently, concentration should be given considerable attention from regulatory authorities.

Evidence of a financial bubble exists in the cryptocurrency market, which arose thanks to the development of a new blockchain technology. By ignoring the risks, investors began to invest in cryptocurrencies, which increased their profitability (in 2017, the price of bitcoin grew from USD 1 thousand to USD 20 thousand). In addition, given that the cryptomarket is not controlled by public authorities, it is used for money laundering, tax evasion, fraud, theft and terrorism financing.

According to an Anti-Phishing Working Group (APWG), from 2017, cybercriminals stole about USD 1.2 billion in cryptocurrency. Taking this into account, state regulatory authorities began studying the legality of cryptocurrency operations. The US Securities and Exchange Commission (SEC) has launched dozens of digital token proceedings due to suspected fraud. Financial Action Task Force (FATF) calls on the international financial community to implement a customer due diligence (CDD) and "know your customer" (KYC) mechanisms for new types of virtual services. First of all, this applies to virtual currency exchanges that must comply with the FATF's "financial institution" standards. In May 2018, the US Department of Justice opened a criminal proceeding on the manipulation of bitcoin prices and other digital currencies by traders. China and Japan have tightened the regulation of cryptocurrency exchanges. Regulatory innovations are immediately reflected in the reduction of the cryptocurrency rate, which increases the market development unpredictability. Despite the fact that the aggregate capitalization of the global cryptomarket is less than $1 \%$ of world GDP, the rapid development of cryptocurrencies, the increase in the number of this market participants, the greater number of their ties with the financial system create risks to financial sustainability.

Today, it is very difficult to predict the future of cryptocurrency. There are investors who believe that bitcoin exceeds all financial assets by all odds. The bitcoin profitability dramatically exceeding the profitability of traditional financial assets confirms this fact. On the other hand, bitcoin shows all the features of a financial bubble. Robert Shiller believes that bitcoin is the best example of a speculative bubble in today's world. Warren Buffett calls bitcoin "rat poison squared". According to the authors, the cryptocurrency market repeats the history of the 1990s stock market, when innovative technologies such as electronic trading platforms began to emerge. On these platforms, as in the current cryptocurrency market, there were no uniform rules of commerce and prices differed significantly (at pres- 
ent, the prices of bitcoin on different trading platforms may vary up to $50 \%$ ), which led to prices manipulation and fraud. However, new technologies gradually became more explored, regulatory rules were developed, which led to the prevention of manipulation and increased the stock market efficiency.

In all cases, the cryptocurrency bubble will have positive effects, because despite irrational dimensions, it is formed influenced by the emergence of a new blockchain technology, which allows you to check transactions and identify contractors through a network of multiple decentralized records. According to Transparency Market Research forecasts, by 2024, the volume of the blockchain market will reach USD 20 billion, demonstrating annual growth of 59\%. Today, financial market participants are exploring the potential of blockchain usage in banking and financial systems, digital media, healthcare, trade, government and other industries. $30 \%$ of the banking sector players are already working on the implementation of the blockchain, and $90 \%$ of the payment companies are planning to implement the technology by 2020. JP Morgan has created a Quocum blockchain platform for interbank payments, the British bank Santande has built an international payment service OnePay FX that will work for cross-border transfers between Europe and South America. In early 2018, Credit Suisse, the Swiss financial corporation, and the Dutch bank ING tested the R3's Corda blockchain platform in the stock market. Using this technology will create a more transparent, liquid and efficient stock mar- ket, as it will allow banking groups to transfer securities ownership to each other more efficiently than traditional systems. Deutsche Boerse, together with the German Central Bank on the basis of the blockchain technology, are also developing a functional prototype for securities settlement in the "supply against payment" mode and the digital securities transfer without intermediaries. The Indian IT-giant Infosys, together with private banks, has developed the Indian Trade Connect pilot trading network aiming to translate business processes into digital format, enhance automation, transparency and efficient risk management.

Thus, blockchain can become a way to solve many problems with regard to increasing future stability in all economic sectors. Thus, as a result of blowing off the bubble, the market will be cleared of excessive speculation and an effective system for its regulation and functioning will be created. Today, in the context of feverish using this technology, it is advisable to introduce tight control from the regulatory authorities (this speaks not only about public authorities, but above all, on the unification of market participants themselves) with new financial innovation instruments.

One of the reasons to form a bubble in the cryptomarket and in other sectors of the financial market is the excess liquidity that resulted from the largest world central banks' quantitative easing (QE) policy. Only four central banks have accumulated about USD 16 trillion on their balance sheets (Figure 2).

Source: Bloomberg data.

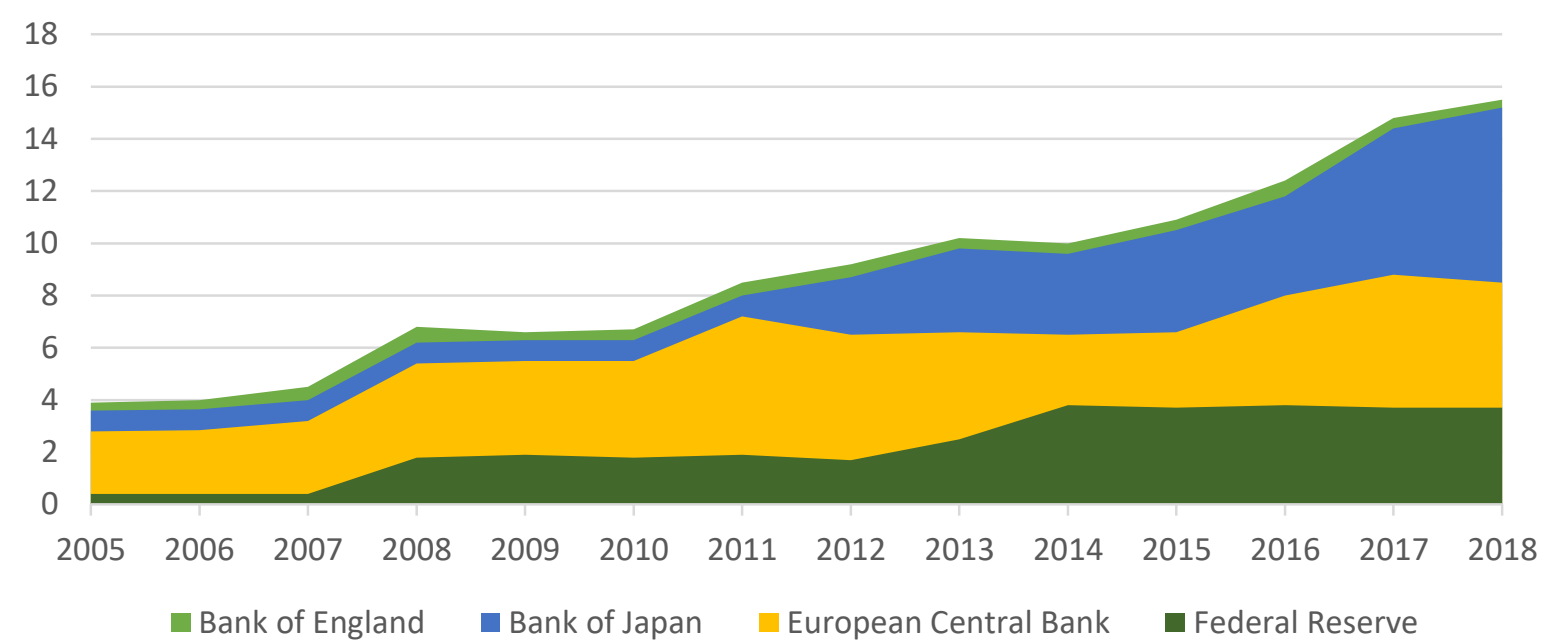

Figure 2. Dynamic of assets of central banks, USD trillion 


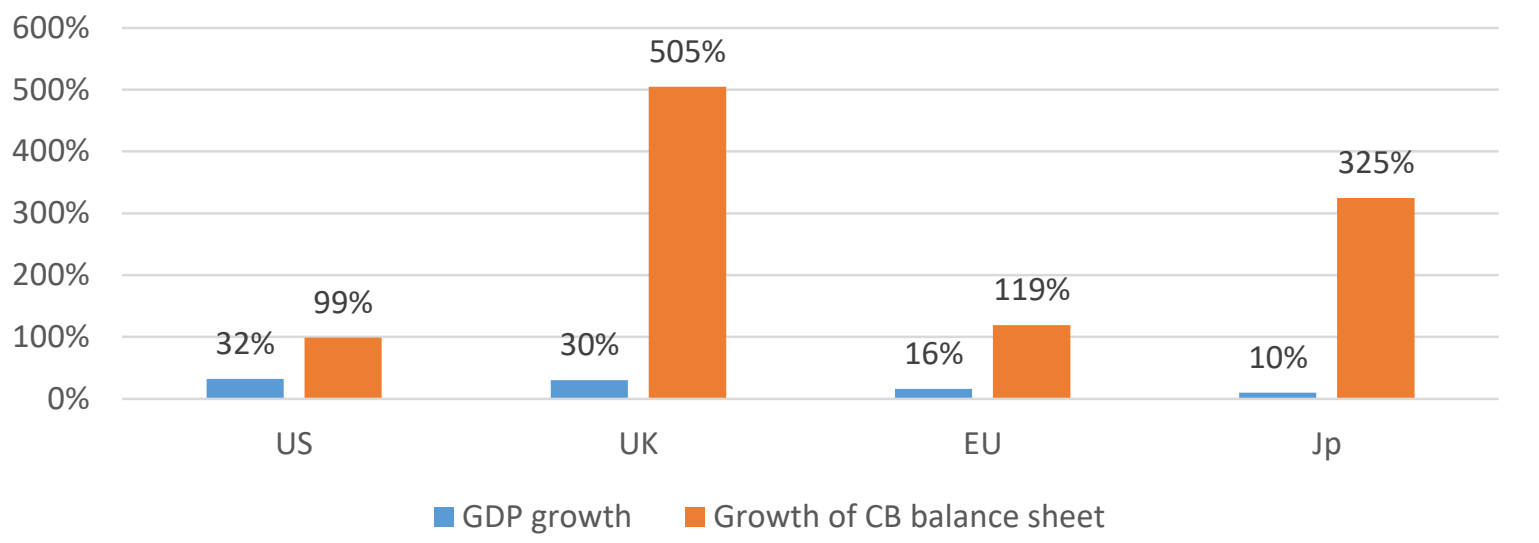

Figure 3. Growth of GDP and assets of the world central banks during the period 2008-2017

The main objective of the quantitative easing policy - stimulating economic growth and combating unemployment - was not achieved, since the recovery of the economy in most developed countries is very moderate (Figure 3).

The main reason that excess liquidity does not turn into loans for the real sector of the economy is the use of modern financial innovative products. Each QE phase led to a rapid increase in prices for financial assets. The world stock market is growing at its highest in history. For example, in the first quarter of $2018,96 \%$ of companies in the S\&P500 index increased their operating profit by $22.6 \%$, which is the highest growth rate for seven years. Thus, it was the policy of central banks that led to an unprecedented rise in prices for financial assets. This exacerbates systemic risks, especially in the context of raising interest rates that have been launched by central banks.

In addition to the banking sector and investment, financial technologies are also introduced in insurance (insurance technologies (InsurTech)), cross-border payments, regulatory supervision (regulatory technologies (RegTech)) and supervisory technology (SupTech). Thus, new financial technologies fundamentally change the entire architecture of the global financial system. Financial innovation increases the complexity of the financial system and becomes a source of its vulnerability. In this context, established practices, regulatory and forecasting tools cease to operate, and the spontaneity of factors that may lead to a new crisis increases. Given that the modern business cycle started in 2009 and has become the second largest one in the whole financial history, then other crisis phenomena can occur at any moment. According to WSJ Survey of Economists, most economists expect a crisis in 2020. However, modern forecasting tools based on deterministic models do not make it possible to predict the specific moment of systemic risk implementation.

Consequently, all financial system participants need to adapt to the introduction of financial technologies. At the same time, financial technologies must first become widely used before society adapts to them. Consequently, a long adaptation process will create a potentially unstable environment.

\section{DISCUSSION}

The global world is entering a new transformational stage in its development. It will be characterized by many crises in various spheres of life (financial transformations, technological singularity, demographic crisis, global warming, energy crisis, environmental pollution, etc.). In this regard, the issue of sustainable development is becoming more and more urgent among many scholars.

When considering the "stability" of the socio-economic systems development, most foreign and domestic authors emphasize the system's ability to return to its original state after the negative influence of external and internal factors. However, given the fact that the current development is characterized by constant rapid changes, the questions arise: "To what state should the system return?" 
and "Will this state be suitable to the new environment?" The global financial system cannot go back to the "past" institutional forms. In the transformation conditions, there is a discrepancy between formal institutions and new forms of interaction, as institutions are slowly developing, and technologies and their applications in complex systems change much faster. This also applies to new financial technologies, which should not just come into existence and be widely used. It is necessary for the financial market participants to adapt to them! The use of the old regulatory tools increases the development uncertainty. In this context, the concept used by various international financial institutions can be efficient, specifically, they define "financial stability as the financial system's ability to effectively perform its functions". But, do modern financial institutions perform their functions? No, they don't! Financial institutions have long ceased to perform their classical functions - state institutions do not regulate what they have to regulate, they participate in the formation of financial bubbles, stock market institutions do not redistribute financial assets to the real economy, commercial banks do not lend to the economy, central banks turn into aggressive investors under negative interest rates, etc. At the same time, they all earn extra profits. Over the past 10 years, the profitability of various financial instruments is increasing at the highest rates. Consequently, an increasing number of market participants do not fulfill their functions, creating systemic risks for the global financial system.

Thus, although stability and equilibrium are necessary conditions for the existence and functioning of the system, but when a new system forms, its development is impossible without eliminating equilibrium, stability and homogeneity. It is precisely this transformational transition that now takes place in the global social and economic system (Shkodina, 2018).

Given that the financial system is one of the most advanced subsystems of economy, then, it is there that the most significant, rapid and progressive changes occur. Under the influence of new financial technologies, the number of participants in the financial system increases and their behavior changes, new phenomena and processes are emerging, which are transformed into fundamen- tal transformation factors. All this leads to the growing complexity of the global financial system, faced with new challenges. Unfortunately, domestic and international control systems are not ready for these challenges. This changes the nature of the systemic risk and strengthens it even more.

Since the economic system relies on human efforts, the conscious activity of economic actors, their ability to co-operate and synchronize their actions based on an agreed decision-making will reduce the cost of development and make the most efficient use of objectively predetermined motion pattern. In this context, the question arises about forming the attractors of the global financial system development, and the role of regulatory institutions (state and non-state) that develop behavioral rules and norms (legislative and regulatory acts) increases.

Given the impact of financial technology on the financial system transformation, regulators need to coordinate their work to stimulate the innovative technologies development, on the one hand, and to create protectors to reduce the risks of their application, on the other hand. In this situation, regulators and professional market players should coordinate their activities to match the rules of the game. The lack of institutional support for new financial technologies is a major catalyst for the financial sector destabilization.

FinTech companies use insider information from cryptocurrency exchanges and manipulate prices, which results in financial bubbles. Lack of trust among new market participants negatively affects the financial system stability. It is important to understand the lack of boundaries between actors in the global financial market. This requires the development of rules for FinTech companies' activity, which will ensure that the financial position of FinTech companies is reliable and meets international prudential standards. In order to attract new, innovative financial market participants, it is necessary to revise the licensing regime for providing financial services. It is important not just to develop standards and rules that will meet national priorities and international environment, but to rebuild a new global financial system as an entire system capable of long-term dynamic equilibrium. 
To strengthen the financial system, government supervision and regulation are needed to test the reliability of the underlying technologies (for example, the Basel approach to banks' internal risk models can be used). The rules of the algorithms underlying the FinTech innovations need to be revised. Decision-making algorithms should work in a way which is not subject to machinations. Recent events affecting the work of Facebook's algorithms prove that standards that the company itself introduces cannot always guarantee security and reliability. According to the authors, "regulatory sandboxes", which test new technologies and business models in a controlled environment, are a positive moment. This enables FinTech companies to come into line with the authorities to ensure the reliability and security of their business. Such a collaborative work will promote trust among mar- ket participants, which is necessary for long-term development. Large market participants that cooperate to develop self-regulation rules for the industry (for example, Winklevoss twins teamed up with Nasdaq Inc to test trading on their stock exchange Gemini Trust Co) provide a good example.

Global perspectives for the blockchain introduction in various areas of life require a legal regulation and a clear definition of a digital token ownership, which is extremely important for financial market players under increasing cybercrime. Market participants need to jointly develop cryptomarket standards and regulations within the Simple Agreement for Future Tokens (SAFT). Different national jurisdictions try to develop their own legal systems, however, according to the authors, a global approach would be more effective.

\section{CONCLUSION}

Thus, under increased global instability, a new institutional system is shaped, new institutions, functional relationships and interdependencies emerge. One of the main factors in the global financial system transformation is financial technologies, which increase operating speed of the financial industry and its profitability, open access to the capital market for new entrants. However, their implementation results in the increased complexity and unpredictability of development, as there are nonlinear correlations in the development of complex systems, which complicates the projected growth.

The mechanisms for using innovative financial technologies need to be refined and the regulatory experience of different countries needs to be integrated. According to the intensity of mass adoption of new financial technologies and public policies (whether it will be a change catalyst or a change inhibitor), institutional changes in the financial system will be gradual and evolutionary, or potentially devastating. Institutionalization and qualitative regulation of new financial technologies will ensure the transparency of the financial system, increase confidence in the FinTech, which will be a key in reducing the development unpredictability.

\section{REFERENCES}

1. Abadi, J., \& Brunnermeier, M. (2018). Blockchain Economics. Retrieved from https://scholar.princeton.edu/sites/default/files/markus/ files/blockchain_paper_v3g.pdf

2. Barrdear, J., \& Kumhof, M. (2016). The Macroeconomics of Central Bank Issued Digital Currencies (Bank of England Staff Working Paper No. 605). Retrieved from https://www.bankofengland. co.uk/-/media/boe/files/workingpaper/2016/the-macroeconomics- of-central-bank-issued-digitalcurrencies.pdf?la=en\&hash $=341 \mathrm{~B}$ 602838707E5D6FC26884588C912 A721B1DC1

3. Bloomberg: business and markets news, data, analysis. Retrieved from https://www.bloomberg.com

4. Bouveret, A. (2018). Cyber Risk for the Financial Sector: A Framework for Quantitative Assessment. Retrieved from https://ssrn.com/ abstract $=3203026$
5. Business Insider Intelligence (n.d.). Retrieved from https://intelligence.businessinsider.com

6. Business Insider (2017). The global fintech landscape: How countries around the world are embracing digital disruption in financial services. Retrieved from http://www. businessinsider.com/the-globalfintech-landscape-report-2017-10

7. Dong, He, Ross, B. Leckow, Vikram Haksar, Tommaso Mancini 
Griffoli, Nigel Jenkinson, Mikari Kashima, Tanai Khiaonarong, Celine Rochon, \& Hervé Tourpe (2017). Fintech and Financial Services: Initial Considerations. Retrieved from https://www.imf. org/en/Publications/Staff-Discussion-Notes/Issues/2017/06/16/ Fintech-and-Financial-ServicesInitial-Considerations-44985

8. Dong, He (2018, June). Monetary Policy in the Digital Age. Finance \& Development, 55(2). Retrieved from http://www.imf.org/external/ pubs/ft/fandd/2018/06/centralbank-monetary-policy-and-cryptocurrencies/he.htm

9. Dresearch (2017). Will the "black boxes" cause the next financial crisis? Retrieved from https:// latest.13d.com/will-the-black-boxes-cause-the-next-financial-crisisalgorithmic-revolution-asset-management-d8827c29b537

10. Foley, Sean, Karlsen, Jonathan R., \& Putniņš, Tālis J. (2018). Sex, Drugs, and Bitcoin: How Much Illegal Activity Is Financed Through Cryptocurrencies? Retrieved from https://ssrn.com/abstract=3102645

11. Galbraith, J. K. (1994). A Short History of Financial Euphoria (130 p.). Penguin Business. Retrieved from https://epdf.tips/a-short-historyof-financial-euphoria-whittle.html

12. Gertrude Chavez-Dreyfuss, \& Dan Grebler (2018). About \$1.2 billion in cryptocurrency stolen since 2017: cybercrime group. Retrieved from https://www.reuters.com/article/ us-crypto-currency-crime/about1-2-billion-in-cryptocurrency-stolen-since-2017-cybercrime-groupidUSKCN1IP2LU

13. Lai, Rose Neng, Van Order, \& Robert A. (2017). Fintech Finance and Financial Fragility - Focusing on China. Retrieved from https:// ssrn.com/abstract $=3075043$

14. PricewaterhouseCoopers (2017). Global FinTech Report 2017. Retrieved from https://www.pwc. com/jg/en/publications/pwc-global-fintech-report-17.3.17-final.pdf

15. Rachel Evans, Sabrina Willmer, Nick Baker, \& Brandon Kochkodin (2017). Black Rockand Vanguard are Less Than a Decade Away from Managing \$20 Trillion. Retrieved from https:// www.bloomberg.com/news/features/2017-12-04/blackrock-andvanguard-s-20-trillion-future-iscloser-than-you-think

16. Sarah Kocianski (2017). The global fintech landscape: How countries around the world are embracing digital disruption in financial services. Retrieved from http://www. businessinsider.com/the-globalfintech-landscape-report-2017-10

17. Shkodina, I., Timoshenkov, I., \& Nashchekina, O. (2018). The impact of financial technology on the transformation of the financial system. Financial and credit activity: problems of theory and practice, 1(24), 417-424.

18. Transparency Market Research (2017). Blockchain Technology Market-Global Industry Analysis, Size, Share, Growth, Trends, and Forecast 2016-2024. Retrieved from https://www.transparencymarketresearch.com/blockchaintechnology-market.html

19. UPFINA (2018). Recession in 2020 is the Base Case. Retrieved from https://upfina.com/recession-in2020-is-the-base-case

20. Will Martin (2018). This chart shows every major technological innovation in the last 150 years - and how they have changed the way we work. Retrieved from http://uk.businessinsider. com/barclays-how-technology-has-changed-the-world2018-4?utm_source=feedly\&utm medium $=$ referral $\& \mathrm{r}=\mathrm{US} \& \mathrm{IR}=\mathrm{T}$ 